\title{
Descentralização da gestão ambiental: análise do processo de criação de organizações municipais de meio ambiente no sul catarinense
}

Daniel Trento do Nascimento e Maria Augusta Almeida Bursðtyn

\section{Introdução}

A questão ambiental passou a fazer parte da vida dos municípios brasileiros com maior ênfase a partir da Constituição Federal de 1988, como se observa, de forma geral, no Artigo 225, em que o meio ambiente é definido como bem de uso comum do povo, sendo responsabilidade do poder público e da sociedade a sua manutenção. De forma específica, o Artigo 23 deixa claras as competências comuns da União, dos estados, do distrito federal e dos municípios para, entre outras coisas, promoverem a proteção do meio ambiente, o combate à poluição, a preservação das florestas, da fauna e da flora.

Embora muitos problemas ambientais extrapolem a territorialidade dos municípios em termos de efeitos, mecanismos, dispersão e responsabilidades, é inegável que o município é o ente administrativo da federação onde os problemas ambientais estão mais próximos da vida do cidadão, cabendo à administração municipal a responsabilidade pela tomada de decisão e execução da gestão ambiental no âmbito local. 
$\mathrm{Na}$ busca de soluções para os problemas estruturais e institucionais da política ambiental brasileira, um dos pressupostos mais fortes nos meios acadêmico, político e governamental tem sido a necessidade de descentralização da política e gestão ambiental. Entretanto, são poucos os estudos que buscam avaliar a real efetividade desses processos no Brasil.

Como mencionam Scardua e Bursztyn (2003), entre os diversos desafios para a gestão ambiental municipal está a descentralização. Pois à medida que os instrumentos de gestão ambiental federal vão sendo implementados, os estados tendem a seguir as diretrizes; porém, essas práticas ainda não encontram a mesma facilidade de ocorrer nos municípios.

Assim, é cada vez mais importante que os municípios tenham capacidade de orga- se que existe um crescimento no processo de estruturação da gestão ambiental no âmbito municipal.

$\mathrm{Na}$ Tabela 1 se observa que houve aumento no número de municípios que apresentam o setor de meio ambiente sendo tratado por algum órgão (SMMA). Numa visão geral, incluindo as secretarias onde a questão de meio ambiente é tratada de forma compartilhada com outro setor, houve um crescimento de mais de $20 \%$ em 6 anos.

Quando se considera apenas secretarias municipais que tratam a área ambiental de forma exclusiva (SMMA exclusiva), o aumento foi de $7 \%$. No que diz respeito à existência de conselhos municipais de meio ambiente (CMMA), constata-se que houve aumento de aproximadamente 13\% no número de municípios com conselhos criados.

Tabela 1: Evolução da estrutura de gestão ambiental municipal (2002 - 2008)

\begin{tabular}{l|c|c|c|c}
\hline Ano da pesquisa & \multicolumn{2}{|c|}{2002} & \multicolumn{2}{c}{2008} \\
\hline $\mathrm{N}^{\mathrm{o}}$ municípios & 5.560 & $\%$ & 5.564 & $\%$ \\
\hline SMMA & 1.752 & 31.51 & 3.078 & 55.32 \\
\hline SMMA exclusiva & 326 & 5.86 & 706 & 12.69 \\
\hline CMMA & 1.895 & 34.08 & 2.650 & 47.63 \\
\hline
\end{tabular}

Fonte: Elaborado pelo autor com base em MUNIC (IBGE, 2002) e MUNIC (IBGE, 2008)

nizarem seu sistema de gestão ambiental e, além disso, tenham uma estrutura capaz de implementar a política ambiental com pessoal capacitado, equipamentos apropriados e recursos financeiros.

Ao se comparar dados relacionados à estrutura dos municípios para gestão ambiental, registrados em 2002 (MuNIC IBGE, 2002), com a situação encontrada em 2008 (MuNIC - IBGE, 2008), verifica-
Diante desse cenário, uma das questões que surgem está relacionada às razões que movem os municípios para a institucionalização da área ambiental. Nesse sentido, procurou-se com este estudo investigar qual o motivo principal que tem levado os municípios a criarem organizações municipais de meio ambiente.

Para tanto, foram selecionados municípios da região sul catarinense, pois é uma 
região que, além de apresentar um processo recente de criação de organizações locais de meio ambiente, tem a peculiaridade de apresentar grande maioria dos municípios adotando forma jurídica de fundações públicas municipais.

Dessa maneira, definiu-se como objetivo de pesquisa identificar os fatores determinantes para o processo de criação das fundações municipais de meio ambiente no sul catarinense. Como metodologia, foram realizadas entrevistas estruturadas e semiestruturadas com atores locais importantes, bem como aplicados questionários aos gestores do órgão ambiental dos municípios.

A pesquisa se apoiou em dados estatísticos secundários (Munic, IbGe, PNud) e dados primários produzidos com os questionários aplicados aos municípios. No total, foram selecionados 10 municípios e foram entrevistados ${ }^{1}$ os responsáveis pelo setor ambiental, podendo ser secretário, presidente ou superintendente - no caso de fundações -, diretores e assessores quando departamentos de meio ambiente.

\section{Descentralização da gestão ambiental}

A descentralização das políticas públicas ambientais é vista como uma das alternativas aos problemas e desafios que os municípios enfrentam na área ambiental. A descentralização pode ser de natureza intergovernamental, intragovernamental ou interinstitucional, funcional ou espacial. Entre algumas alternativas para a descentralização das políticas públicas, podem ser destacadas a estadualização, a municipalização, a regionalização e a privatização.

Para Teixeira e Santana (1995), a descentralização impõe-se como uma estratégia de primeira importância para reverter a tendência altamente centralizadora do modelo de gestão vigente. Porém, não basta apenas descentralizar; concomitantemente faz-se necessária uma nova integração como estratégia para garantir a articulação vertical e horizontal entre os diversos níveis de fluxos dentro da administração pública. Os autores citam outros aspectos que são essenciais para atingir descentralização e integração:

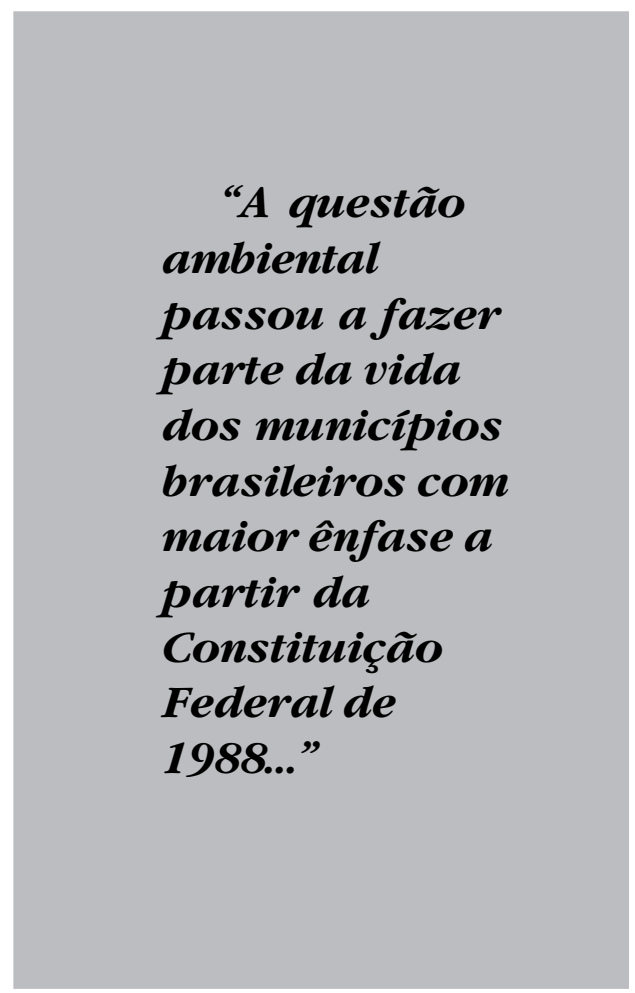

a) fortalecimento da delegação da competência executiva aos diversos níveis da administração, transferindo-a, quando devido, para os estados, municípios, instâncias setoriais, instituições da administração indireta etc.;

b) descentralização das estruturas fiscalizadoras fazendo com que as atividades de fiscalização e controle permeiem 
organicamente a rede administrativa, tornando a função fiscalizadora mais próxima da fonte de execução da atividade correspondente e, portanto, da população;

c) consequente apoio aos órgãos com poderes descentralizados como câmaras legislativas, grupos executivos de projetos locais, organizações sociais distritais e de bairros entre outras, para que exerçam atividades administrativas e fiscalizadoras de processos e projetos.

A competência municipal para licenciar atividades com potencial poluidor é apenas para as atividades com impacto local, ou aquelas especificadas por lei ou convênio como sujeitas de delegação do estado para o município. As competências para o licenciamento são definidas de acordo com a abrangência dos impactos: dois ou mais estados (IBAMA); dois ou mais municípios (Órgão Estadual de Meio Ambiente OEMA); local (órgão municipal responsável pela gestão ambiental ou Oema), caso o município ainda não esteja habilitado para tal.

Um entrave à descentralização é a falta de capacidade institucional de alguns estados e muitos municípios. Muito embora existiram algumas tentativas de descentralização antes, foi só após a democratização que começou a existir uma revisão no papel do Estado brasileiro, e o poder local passou a ganhar destaque no contexto federativo.

Kliksberg (2000) apud Scardua e Bursztyn (2003) afirma que os dois riscos principais da descentralização na área ambiental são: as grandes diferenças entre os municípios; e controle da sociedade local pelas oligarquias locais.

De acordo com os mesmos autores, as experiências brasileiras recentes de descentralização de políticas públicas não permitem vislumbrar um cenário muito otimista, pois o padrão histórico de captura do Estado no âmbito local por práticas perniciosas (clientelismo e patrimonialismo, por exemplo) ainda está muito arraigado na cultura política do país.

Além disso, é importante observar o argumento de Azevedo, Pasquis e Bursztyn (2007), de que a descentralização na área ambiental está sendo forçada de cima para baixo, sem a observação das capacidades de governança das esferas estaduais e municipais. Como consequência, na opinião dos autores, a descentralização estaria sendo apenas transferência de responsabilidades sem recursos em vez de um compartilhamento de competências.

Novaes (2007) segue o mesmo raciocínio, como se observa:

Se o governo federal não tem estrutura para um licenciamento e monitoramento competentes, como será com o governo estadual e/ou municipal, muito menos provido de recursos, muito mais sujeito a pressões dos poderes político e econômico locais? Embora a descentralização seja teoricamente desejável, na prática os problemas têm se verificado em todas as partes do país onde ela ocorre. $\mathrm{Na}$ verdade, parece muito mais um "repasse do mico" que qualquer outra coisa (Novaes, 2007, p. A2).

Purcell e Chirstopher (2005) argumentam que nem sempre a tomada de decisão no ambiente local é benéfica socialmente e ecologicamente. Para os autores, as escalas são socialmente construídas por meio de disputas políticas. Um arranjo escalar em que os recursos ou decisões são controlados localmente não garante que serão ecologicamente ou socialmente mais justos que outro arranjo, seja regional, nacional 
ou global; já que os resultados de um arranjo são dependentes da agenda política daqueles que são os responsáveis pela sua implementação.

Por outro lado, se percebe que a descentralização vem ocorrendo e firmando-se como uma tendência a ser acentuada nos próximos anos. Parece um caminho sem volta, como se observa nos dados do IBGE (Munic), que vem mostrando um aumento ano a ano no número de municípios que passam a estruturar-se para a gestão ambiental. Nesse sentido, é válido citar o papel que as Comissões Tripartites têm desempenhado nos estados.

A Comissão Tripartite foi criada para fortalecer o processo de descentralização da política e gestão ambiental no Brasil, e é um instrumento que visa construir espaços de diálogo entre os entes federados em busca de uma gestão compartilhada na área ambiental. Foi criada pela portaria do Ministério do Meio Ambiente (MMA) $\mathrm{n}^{\circ} 189$, de março de 2001, e é formada pelo MMA, pela Associação Brasileira de Entidades Estaduais de Meio Ambiente (ABema) e pela Associação Nacional de Municípios e Meio Ambiente (Anamma).

\section{Gestão ambiental municipal}

A gestão ambiental municipal é um processo político-administrativo que compete ao poder público local (Executivo e Legislativo) implementar, formular e avaliar políticas ambientais, com a participação da sociedade, visando assegurar qualidade ambiental e qualidade de vida aos cidadãos (Philippi JR, 2007).

Como instrumentos de gestão ambiental municipal podem ser citados os seguintes: plano diretor; código de obras; lei de uso e ocupação do solo; lei de parcelamento do solo; código de posturas urbanas; zoneamento ambiental; estatuto da cidade; licenciamento ambiental; alvará de localização e funcionamento de atividades; agenda 21; educação ambiental; entre outros.

Importante componente da gestão ambiental municipal é o órgão executivo municipal de meio ambiente. Não é necessário que seja criada uma secretaria ou um departamento específico para tratar da questão ambiental, pois, desde que seja definido por lei, qualquer outro órgão da estrutura administrativa da prefeitura municipal pode executar as funções de gestão ambiental.

Os eixos estruturais para a política e a gestão ambiental municipal são os que seguem: democratização da gestão ambiental; controle social, transparência e acesso à informação; articulação do governo local com as demais esferas de governo; corresponsabilidade; princípio da subsidiaridade; compromisso compartilhado com os Objetivos do Milênio, com destaque para o objetivo 7 - garantir a sustentabilidade ambiental (MARcATo e RibeIRo, 2002).

A estrutura de gestão da política municipal de meio ambiente, assim como a política nacional, deve ser constituída por um conselho municipal de meio ambiente (órgão superior) e um órgão executivo de meio ambiente (órgão central), podendo este ser compartilhado com outro setor e órgãos seccionais (outros órgãos da administração municipal, fundações, autarquias, etc.). Em complemento, para a viabilização da política municipal de meio ambiente, os municípios podem criar um fundo municipal de meio ambiente (Souza et al., 2003).

De acordo com Souza et al. (2003), as maiores dificuldades das administrações 
municipais na implementação da política municipal de meio ambiente são: inadequação dos instrumentos à estrutura de gestão; falta de integração; baixa capacitação técnica e falta de recursos financeiros.

\section{Fundações públicas}

Como nesta pesquisa um dos objetos de análise são as fundações municipais de meio ambiente, é fundamental entender as principais características desse tipo de organização.

A administração pública pode ser dividida em duas partes: a) administração direta, composta por órgãos ligados diretamente ao órgão executivo central como, p. ex., ministérios (União), secretarias (estados ou municípios); b) administração indireta, que possui maior autonomia em relação ao órgão executivo central e pode ser dividida em: autarquias, fundações públicas, empresas públicas e empresas de economia mista.

As fundações públicas podem ser definidas como entidades dotadas de personalidade jurídica de direito público, sem fins lucrativos, criadas por meio de autorização legislativa (lei específica e regulamentada por decreto) para o desenvolvimento de atividades de interesse público, como educação, cultura e pesquisa (FGV, 2008).

Dallari (1995) define fundação como sendo a vinculação de um patrimônio a determinado fim, atribuindo-lhe personalidade jurídica. De acordo com o mesmo autor, tem sido comum no Brasil apontar as fundações como solução ótima para problemas relacionados à deficiência de recursos, à falta de flexibilidade e à necessidade de independência política.
A fundação pode assinar contratos, pode ser proprietária e receber doações, pode mover ações judiciais, podendo, em síntese, agir como se fosse uma empresa legalmente constituída. Além disso, fica sujeita ao cumprimento de obrigações, como o pagamento de impostos e o respeito aos compromissos que tiver assumido com terceiros; ficando, ainda, sujeita a algumas regras legais que só se aplicam às fundações, como o controle permanente pelo Ministério Público (Dallari, 1995).

Em 1916, o Código Civil considerava as fundações como pessoas jurídicas de direito privado, assim como as sociedades civis, científicas, as associações de utilidade pública, as sociedades mercantis e os partidos políticos.

As fundações criadas pelo poder público no Brasil surgiram há mais de 60 anos, mas por um bom tempo houve questionamento e resistência do direto brasileiro que, mesmo sendo instituídas pelo poder público, considerava as fundações com personalidade jurídica de direito privado. Entretanto, hoje já são aceitas como sendo de direito público e seu funcionamento é muito parecido com o das autarquias (DALLARI, 1995).

Silva et al. (2009) identificam três correntes para caracterizar as fundações. A primeira, mais antiga, defende a natureza privatística de todas as fundações instituídas pelo poder público; ou seja, o fato de ser o Estado o instituidor não faz com que essa entidade deixe de ser de direito privado. Essa era a opinião clássica de Meirelles (1990), para quem constituíam uma contradictio in terminis expressões como autarquias fundacionais ou fundações públicas. 
A segunda corrente, minoritária, defende que, após a promulgação da Constituição de 1988, o poder público somente poderia instituir fundações de direito público. E, por fim, a corrente mais aceita e adotada pelo Supremo Tribunal Federal (STF) defende que as fundações públicas de natureza de direito público são caracterizadas como verdadeiras autarquias, razão porque são denominadas, algumas vezes, de fundações autárquicas ou autarquias fundacionais.

Em relação às aparentes vantagens das fundações, Dallari (1995) menciona que tanto a prometida flexibilidade administrativa quanto a liberdade para celebrar contratos de gestão foram restringidas pela Constituição de 1988. De acordo com o Artigo 37, todos os componentes da administração pública estão sujeitos às mesmas regras, como se observa no caput do Artigo: "A administração pública direta e indireta de qualquer dos Poderes da União, dos estados, do distrito federal e dos municípios obedecerá aos princípios de legalidade, impessoalidade, moralidade, publicidade e eficiência".

No que tange à mística de que a fundação pode ser uma fonte milagrosa de recursos, Dallari (1995) é enfático ao mencionar que "é ilusória a imagem da fundação como fonte milagrosa de recursos. Como regra, a fundação deverá ser instituída com base num patrimônio rentável, capaz de produzir o suficiente para atingir os objetivos pretendidos".

Além disso, no inciso XIX do mesmo artigo, tem-se que somente por lei específica poderá ser criada autarquia e autorizada a instituição de empresa pública, de sociedade de economia mista e de fundação, cabendo à lei complementar, neste último caso, definir as áreas de sua atuação.
As fundações de meio ambiente e a descentralização da gestão ambiental em Santa Catarina

O próprio órgão executor da política ambiental no Estado de Santa Catarina é uma fundação: a Fundação do Meio Ambiente (FATMA). A Fatma é uma fundação pública, vinculada à Secretaria de Estado do Desenvolvimento Econômico Sustentável (SDS), entidade de caráter

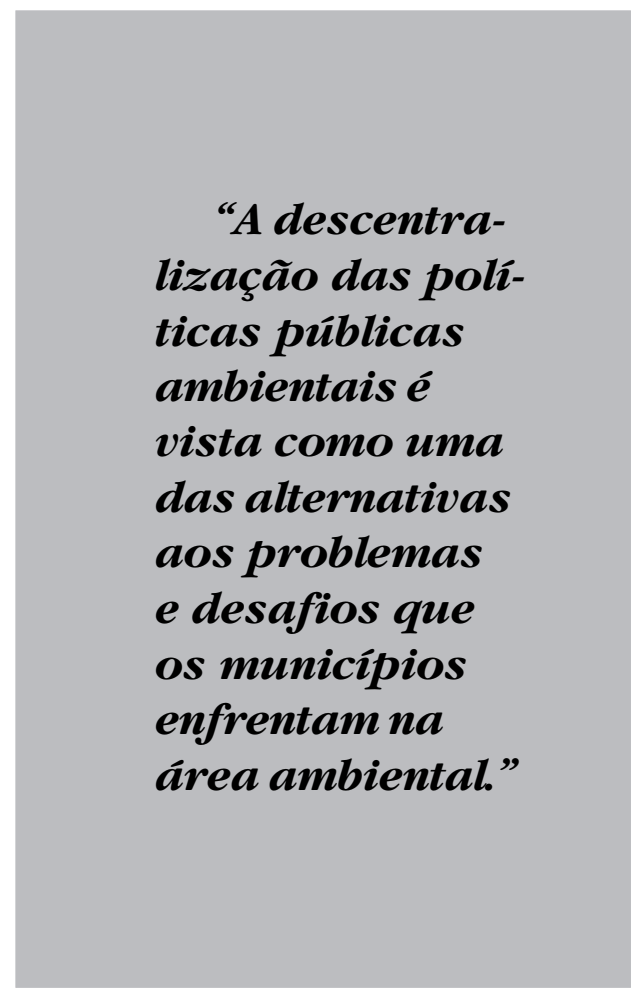

científico, sem fins lucrativos, instituída pelo decreto $\mathrm{n}^{\circ}$ 662, de 30 de julho de 1975. Sua jurisdição abrange todo o território catarinense e, em conformidade com o artigo $\mathrm{n}^{\circ}$ 66, da lei $\mathrm{n}^{\circ} 9.831$, de 17 de fevereiro de 1995, tem por objetivo: a) executar projetos específicos, incluídos os de pesquisa científica e tecnológica, de defesa e preservação ecológica; b) fiscalizar, 
acompanhar e controlar os níveis de poluição urbana e rural; c) participar na análise das potencialidades dos recursos naturais com vistas ao seu aproveitamento racional; d) promover a execução de programas visando a criação e administração de parques e reservas florestais; e) executar as atividades de fiscalização da pesca, por delegação do governo federal.

O processo de descentralização da gestão ambiental no estado é coordenado principalmente pelo programa de municipalização conduzido pela Fatma. Algumas cidades como Blumenau e Joinville já possuem órgãos municipais de gestão ambiental há mais de 20 anos. Aliás, a Fundação Municipal de Meio Ambiente de Blumenau (Faema) foi o segundo órgão ambiental municipal a ser criado no país, em 1977.

Vários municípios têm criado seus órgãos municipais de meio ambiente em Santa Catarina, principalmente após o ano 2000. Esse fenômeno se verifica fortemente na região sul do estado, onde vários municípios acabaram de criar seus órgãos municipais ou estão em fase de criação.

Nesse processo, além dos municípios se estruturarem para fazer a gestão ambiental, alguns deles têm se habilitado para dar procedimento ao licenciamento ambiental de atividades de impacto local. Um dos instrumentos que a Fatma tem utilizado para apoiar os municípios são os convênios de cooperação técnica e institucional. A base do processo de municipalização da gestão ambiental no estado é a lei no 9.638/81, que dispõe, entre outras coisas, sobre os diversos instrumentos da Política Nacional do Meio Ambiente.

Em conjunto com a referida lei, a descentralização da gestão ambiental municipal em Santa Catarina fundamenta-se também em outras leis, decretos e resoluções federais e estaduais ${ }^{2}$.

De acordo com o Art. $1^{\circ}$ do decreto estadual $n^{\circ}$ 620, de 27 de agosto de 2003, o Programa de Descentralização das Ações de Gestão Ambiental no Estado de Santa Catarina tem, entre outros, os seguintes objetivos: a descentralização e gestão ambiental compartilhada nos municípios do estado; agilidade e otimização do processo de licenciamento ambiental; delegação do licenciamento de atividades de impacto ambiental local aos municípios habilitados; e fomento à criação e implementação de instituições municipais de meio ambiente.

Como instrumentos para a descentralização, o Programa de Descentralização das Ações de Gestão Ambiental no Estado de Santa Catarina adota os seguintes:

a) a celebração de convênio de cooperação técnica e institucional entre a SDS, a Fatma, os municípios, as instituições da sociedade civil e demais órgãos da administração pública estadual;

b) o programa contínuo de capacitação, sob responsabilidade da SDS, objetivando formar e atualizar os servidores municipais para atuação nas atividades de gestão ambiental;

c) a criação e o fortalecimento dos conselhos municipais de meio ambiente, paritários e representativos, e dos fundos municipais de meio ambiente;

d) fomento à elaboração e implementação de legislação municipal de meio ambiente, das políticas municipais de meio ambiente nos municípios conveniados, com a cooperação técnica da Fatma e da SDS;

e) a definição das atividades de impacto ambiental e de critérios para o exercício da competência do licenciamento ambiental municipal, por meio de resolução aprovada pelo Consema. 
Os municípios do Estado de Santa Catarina que passam a licenciar as atividades de impacto local dispõem como base a resolução 02/2006 do Consema, que estabelece as atividades de impacto local para fins do exercício da competência do licenciamento ambiental municipal, bem como os critérios necessários para o licenciamento por meio de convênio, das atividades potencialmente poluidoras previstas em listagem aprovada pelo Consema.

De acordo com o Art. $4^{\circ}$ da mesma resolução (02/2006), para requerer a habilitação o município deverá ter os seguintes pré-requisitos aprovados:

a) Comprovação de implementação do conselho municipal de meio ambiente, com caráter deliberativo, e composto de forma paritária entre as instituições governamentais e não governamentais;

b) Decreto municipal declarando o nível de complexidade em que o município fará o licenciamento ambiental municipal;

c) Declaração do prefeito de que assume o compromisso de manter em seus quadros servidores públicos na condição de técnicos legalmente habilitados e com anotação de responsabilidade técnica (ART) ou de função técnica (AFT), para apreciarem os aspectos técnicos sob análise.

Ao exigir uma estrutura mínima com servidores públicos na condição de técnicos legalmente habilitados, não se estabelece conjuntamente a necessidade de um órgão exclusivo para tratar de meio ambiente. Ao celebrar os convênios de cooperação técnica, o que se exige é a necessidade de órgão técnico-administrativo da estrutura do órgão municipal competente com atribuições específicas ou compartilhadas na área de meio ambiente, dotado de corpo técnico multidisciplinar, legalmente habilitado com anotação de responsabilidade técnica ou de função técnica, para análise e avaliações de impactos ambientais.

Entretanto, o que se observa é que a grande maioria dos municípios habilitados ${ }^{3}$ para licenciar possue um órgão exclusivo e um fato interessante é que quase todos são fundações municipais de meio ambiente, com uma única exceção, como se observa no Quadro 1 a seguir.

Sabe-se que a causa da opção pela figura jurídica de fundação pública pode ter vários motivos, entre os quais, como visto em Dallari (1995), podem estar maior autonomia do órgão executivo central, melhor fonte de recursos financeiros, e maior flexibilidade.

É importante lembrar que, para o município iniciar o processo de licenciamento ambiental, existem vários requisitos a serem atendidos como, p. ex., a existência de conselho de meio ambiente paritário e deliberativo, política de meio ambiente local, entre outros instrumentos. Estes só podem ser instituídos na forma de lei, o que vem a configurar uma força maior à presente pesquisa, pois não está se analisando apenas a criação do órgão municipal de meio ambiente, mas também leis e regulamentos necessários para a implementação da gestão ambiental no âmbito local.

\section{Caracterização dos municípios estudados}

Os municípios selecionados para esta análise pertencem à região sul de Santa Catarina e foram selecionados por já possuírem ou estarem em vias de criação do seu órgão municipal de meio ambiente. A região sul catarinense possui uma área 
Quadro 1: Municípios catarinenses habilitados para realizar licenciamento das atividades de impacto local

\begin{tabular}{|l|l|}
\hline Municípios & Órgão municipal de meio ambiente - ano de criação \\
\hline Blumenau & Fundação Municipal de Meio Ambiente (Faema) - 1977 \\
\hline Joinvile & Fundação Municipal do Meio Ambiente (Fundema) - 1990 \\
\hline São José & Fundação Municipal do Meio Ambiente e Agricultura Pedra Branca - 1997 \\
\hline Itajaí & Fundação Municipal do Meio Ambiente de Itajaí - 2000 \\
\hline Itapema & Fundação Ambiental Área Costeira de Itapema (FAACI) - 2001 \\
\hline Içara & Fundação do Meio Ambiente do Município de Içara (Fundai) - 2002 \\
\hline Palhoça & Fundação Municipal do Meio Ambiente de Palhoça - 2003 \\
\hline Xanxerê & Secretaria Municipal de Políticas Ambientais - 2003 \\
\hline Jaraguá do Sul & Fundação Jaraguaense de Meio Ambiente (Fujama) - 2005 \\
\hline Laguna & Fundação Lagunense do Meio Ambiente - 2006 \\
\hline Lauro Müller & Fundação Municipal do Meio Ambiente de Lauro Muller - entre 2006 e 2008 \\
\hline Orleans & Fundação Ambiental Municipal de Orleans (Famor) - 2007 \\
\hline Forquilhinha & Fundação Ambiental Municipal de Forquilhinha - 2007 \\
\hline Criciúma & Fundação Municipal de Meio Ambiente de Criciúma (FAMCRI) - 2008 \\
\hline Cocal do Sul & Fundação Municipal de Meio Ambiente (Fundac) - 2009 \\
\hline Morro da Fumaça & Fundação de Meio Ambiente do Morro da Fumaça (Fumaf) - 2009 \\
\hline
\end{tabular}

Fonte: Fatma, 2009

total de $9.709,247 \mathrm{~km}^{2}$ e uma população de aproximadamente 925.177 habitantes (IBGE, 2010).

Dos municípios analisados, a grande maioria é pertencente à microrregião da Associação dos Municípios da Região Carbonífera (Amrec): Criciúma, Cocal do Sul, Forquilhinha, Içara, Lauro Müller, Morro da Fumaça e Urussanga. Da região da Associação dos Municípios da Região de Laguna (Amurel) foram selecionados dois municípios: Tubarão e Sangão. A única exceção é do Município de Itapema, que faz parte da região do Vale do Itajaí.
Entretanto, devido ao acesso do pesquisador aos gestores ambientais do município e à relevância da experiência de Itapema com a gestão ambiental municipal, procurou-se também inserir este município na análise.

A seguir apresenta-se o mapa do Estado de Santa Catarina com detalhe para os municípios selecionados.

É válido ressaltar que a região de estudo é grande produtora de carvão mineral, atividade que gerou um passivo enorme devido à degradação, dando origem ao decreto presidencial $n^{\circ} 85.206 / 80$, 


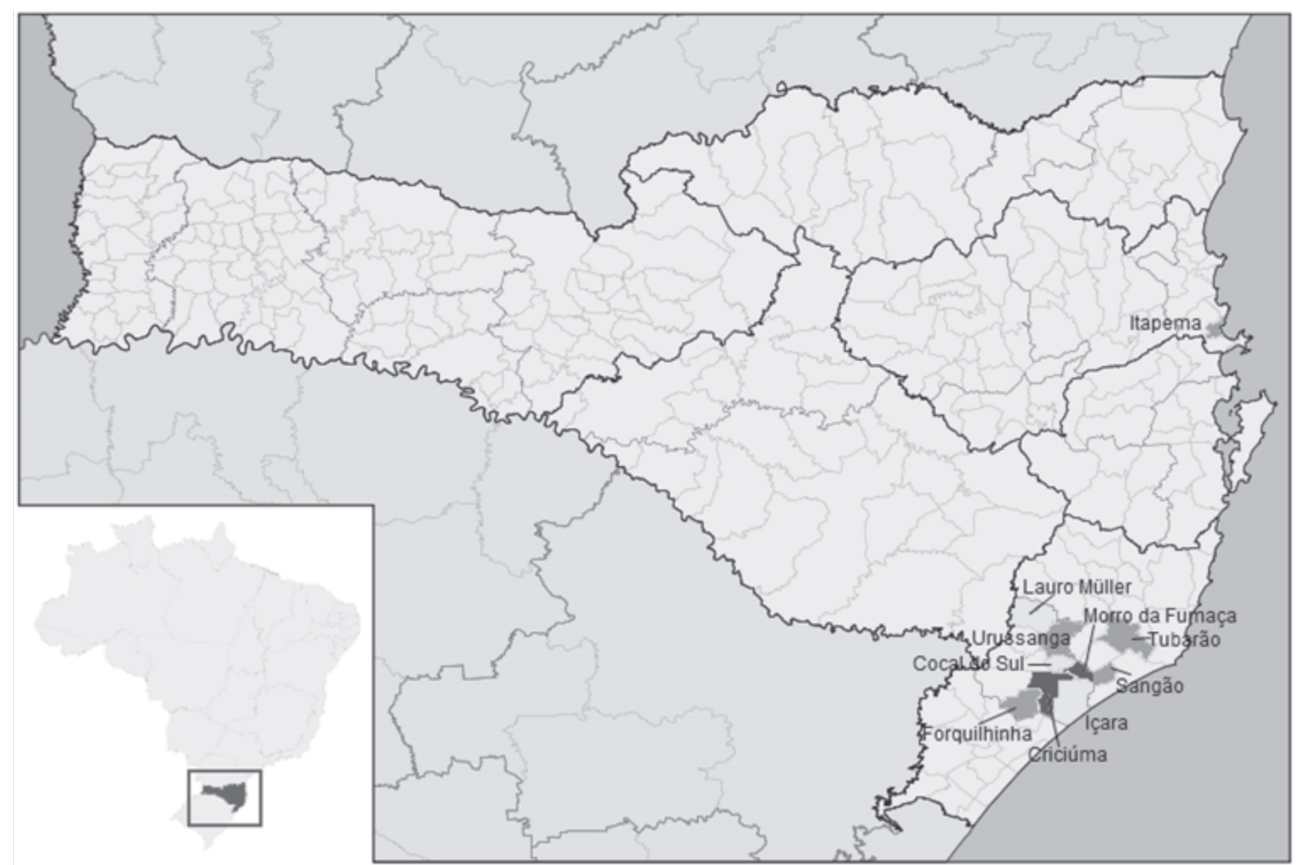

Figura 1: Mapa de Santa Catarina com destaque para os municípios estudados

Fonte: Adaptado de Abreu, 2009 e IBGE, 2009a.

considerando a região carbonífera como a " $14^{a}$ área crítica para efeitos de controle de poluição e conservação do meio ambiente" no Brasil. Além disso, em 2000 foi publicado no Diário Oficial da União a criação do Comitê Gestor para a Recuperação Ambiental da Bacia Carbonifera de Santa Catarina junto ao Ministério do Meio Ambiente (MMA), com o objetivo de articular, coordenar e supervisionar as ações para a recuperação ambiental da região carbonífera do Estado de Santa Catarina.

Outro dado importante a respeito dos municípios estudados se relaciona com suas bacias hidrográficas. A maior parte dos municípios analisados pertence à Bacia do Rio Urussanga, uma das mais poluídas do Brasil devido aos rejeitos do carvão.

Visto isso, pode-se ter uma noção da importância e responsabilidade dos órgãos locais para a gestão ambiental, tendo em vista a cultura econômica regional baseada na exploração intensa de recursos naturais.

Dos municípios selecionados, Criciúma, Cocal do Sul, Forquilhinha, Içara, Lauro Müller, Morro da Fumaça e Itapema já celebraram convênio de cooperação técnica e institucional com o órgão estadual para proceder ao licenciamento ambiental das atividades de impacto local. (Figura 1). 
Em relação aos principais desafios para a gestão ambiental na região, de acordo com Scheibe et al. (2006), alguns pontos importantes a serem observados são:

a) A importância da preservação das florestas para que se mantenham os recursos hídricos e não venham a se desencadear processos erosivos de caráter catastrófico. Nesse sentido, é sugerida a implantação de uma APA (Área de Proteção Ambiental) em toda a encosta da Serra Geral na região sul catarinense;

b) A necessidade de projetos de adequação do manejo agrícola, visando controlar a erosão e aumentar a produtividade;

c) A importância de se incentivar a silvicultura e a fruticultura;

d) A necessidade de se estabelecer padrões de uso adequado das áreas costeiras; e) A urgência na regulamentação do uso do solo urbano,via planos diretores; e

f) Áreas de mineração: há necessidade de planos de recuperação das áreas já mineradas e, urgentemente, de monitoramento efetivo das atividades em curso, a fim de evitar a continuidade dos processos de degradação ambiental. Para as áreas de mineração do carvão, deve ser implementado um zoneamento ambiental e diretrizes específicas, visando administrar os conflitos e racionalizar o uso dos recursos hídricos regionais. (Tabela 2).

\section{Análise dos dados da pesquisa}

Neste tópico são apresentados os dados primários obtidos por meio de entrevistas e aplicação de questionários a todos os gestores ambientais dos municípios selecionados. A pesquisa foi feita nos meses de junho e julho de 2009.

Tabela 2: Características socioeconômicas dos municípios estudados

\begin{tabular}{|c|c|c|c|c|c|c|}
\hline Município & Área km² * & População * & PIB RS ** & $\begin{array}{c}\text { PIB per } \\
\text { capita } \mathrm{R} \$ \text { ** }\end{array}$ & IDH $* * *$ & $\begin{array}{l}\text { Ano de } \\
\text { criação }^{\text {****** }}\end{array}$ \\
\hline Criciúma & 235,6 & 192.308 & $2.366,248$ & 12.571 & $\begin{array}{l}0,822 \\
\text { (elevado) }\end{array}$ & 1925 \\
\hline Cocal do Sul & 71,2 & 15.171 & 231.444 & 15.354 & $\begin{array}{l}0,823 \\
\text { (elevado) }\end{array}$ & 1991 \\
\hline Forquilhinha & 181,9 & 22.548 & 356.685 & 16.576 & $\begin{array}{l}0,797 \\
\text { (médio) }\end{array}$ & 1989 \\
\hline Içara & 292,7 & 58.859 & 589.558 & 10.449 & $\begin{array}{l}0,780 \\
\text { (médio) }\end{array}$ & 1961 \\
\hline Lauro Müller & 270,5 & 14.366 & 132.935 & $9.951,00$ & $\begin{array}{l}0,800 \\
\text { (elevado) }\end{array}$ & 1956 \\
\hline Morro da Fumaça & 82,9 & 16.126 & 265.878 & $16.452,00$ & $\begin{array}{l}0,804 \\
\text { (elevado) }\end{array}$ & 1962 \\
\hline Sangão & 83,0 & 14.402 & 72.501 & $7.540,00$ & $\begin{array}{l}0,794 \\
\text { (médio) }\end{array}$ & 1992 \\
\hline Tubarão & 300,2 & 97.281 & 1.111 .494 & $11.788,00$ & $\begin{array}{l}0,842 \\
\text { (elevado) }\end{array}$ & 1836 \\
\hline Urussanga & 240,4 & 20.222 & 274.427 & $14.235,00$ & $\begin{array}{l}0,845 \\
\text { (elevado) }\end{array}$ & 1878 \\
\hline Itapema & 59,0 & 45.814 & 306.593 & $8.900,00$ & $\begin{array}{l}0,835 \\
\text { (elevado) }\end{array}$ & 1962 \\
\hline
\end{tabular}

Fontes: *Área e estimativa populacional (IBGE, 2010); **Produto Interno Bruto dos Municípios 20022005 (IBGE, 2007); ***Ranking do IDH-M dos municípios do Brasil (PNUD, 2000); ****Governo do Estado de Santa Catarina (2009). 
No Gráfico 1 é apresentada a forma jurídica do órgão encarregado da gestão ambiental no município e no quadro 2 é detalhado o tempo de existência do órgão de gestão ambiental em cada um dos municípios estudados.

Como pode ser observado, mais da metade dos municípios analisados possuem como órgão responsável pela área ambiental uma fundação pública. Nota-se também que mais de $50 \%$ delas existem há menos de dois anos, o que configura um processo recente de fortalecimento e institucionalização da gestão ambiental na região estudada.

No que diz respeito ao motivo principal para a criação do órgão, a maioria dos entrevistados afirmou que a necessidade de maior agilidade no licenciamento foi a principal causa da criação. Também atribuíram tal criação a uma maior preocupação do Executivo municipal para com a temática ambiental.

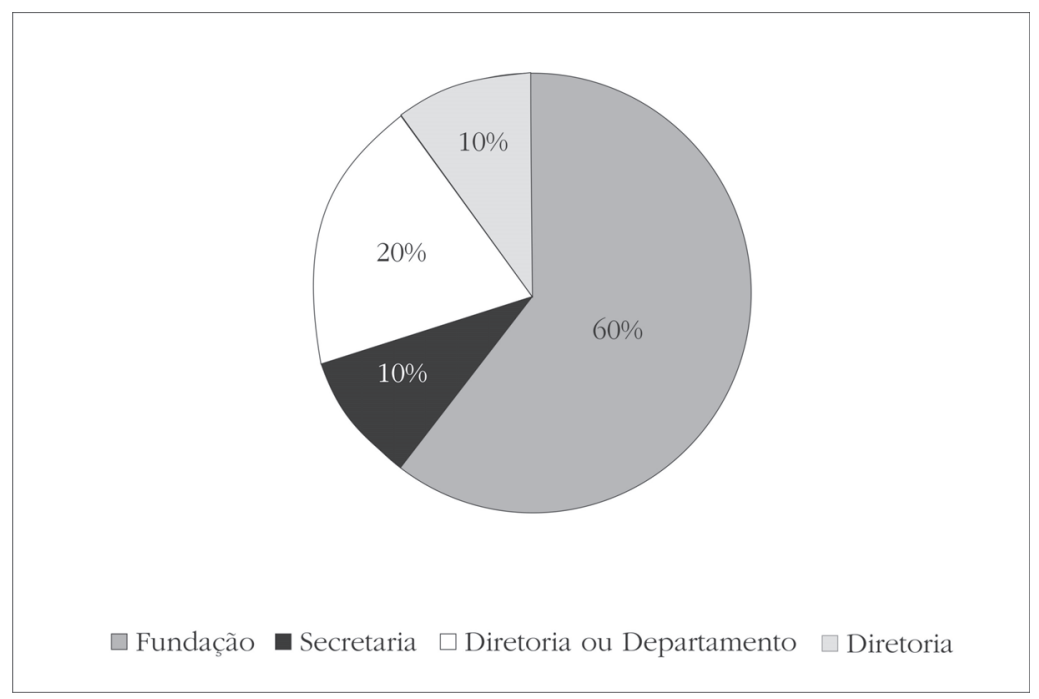

Gráfico 1: Órgão encarregado da gestão ambiental municipal

Fonte: Dados coletados na pesquisa de campo, 2009.

Quadro 2: Tempo de existência do órgão municipal de meio ambiente

\begin{tabular}{|l|l|}
\hline $\begin{array}{l}\text { Há quanto tempo possui órgão executivo } \\
\text { de gestão ambiental }\end{array}$ & \multicolumn{1}{c|}{ Municípios } \\
\hline Em fase de criação & Sangão, Tubarão e Urussanga \\
\hline Menos de 2 anos & $\begin{array}{l}\text { Criciúma, Cocal do Sul, Forquilhinha, Lauro } \\
\text { Müller, Morro da Fumaça }\end{array}$ \\
\hline Mais de 5 anos & Içara e Itapema \\
\hline
\end{tabular}

Fonte: Dados coletados na pesquisa de campo, 2009. 
Essa necessidade de maior agilidade deixa claro que a lentidão e a sobrecarga do órgão estadual têm sido uma das principais causas para a criação do órgão municipal de meio ambiente. É importante notar que apenas um município comentou sobre influência do programa estadual de municipalização da gestão ambiental, e um município afirmou ter sofrido influência das boas práticas de outros municípios, bem como aumento das reclamações da sociedade, mostrando que um dos fatores determinantes para a decisão local foi a ineficiência do órgão estadual. (Gráfico 2).

Em relação ao motivo pelo qual os municípios têm optado pela figura jurídica das fundações públicas em vez de secretaria municipal de meio ambiente, obteve-se o resultado conforme mostrado no Gráfico 3.

Observa-se que a grande maioria (80\%) dos municípios estudados que tem optado por fundação, atribui isso à necessidade de maior autonomia e independência do órgão executivo central do município. Por outro lado, é importante ressaltar que, para que o município possa se habilitar a licenciar, é necessário que atenda alguns requisitos como a criação de instrumentos legais importantes para implementar a gestão ambiental. Dessa forma, se observa que na grande maioria dos municípios o órgão ambiental foi criado em conjunto com outro instrumento.

Verifica-se assim que essa exigência legal é um fator importante que contribui para a qualificação do processo de institucionalização de estruturas que favorecem a governança local e a gestão ambiental. (Quadro 3).

Outro ponto abordado na pesquisa relaciona-se ao processo de discussão junto à Câmara de Vereadores para a criação do órgão e dos instrumentos legais relacionados, visto que, como se tratam de leis municipais, necessitam ser submetidas ao órgão legislativo do município.

Dos municípios que responderam ao questionário, metade afirmou que os projetos de lei foram aprovados sem problemas (Içara, Forquilhinha e Urussanga) e outra metade afirmou ter sido um processo muito debatido e questionado (Criciúma, Cocal do Sul e Sangão ${ }^{4}$ ). (Gráfico 4).

No que diz respeito ao relacionamento dos órgãos municipais de meio ambiente com os demais órgãos componentes do Sisnama, pertencentes às outras esferas (federal e estadual), identificou-se que os órgãos estaduais com função de executar a política ambiental são instituições com as quais os municípios mantêm melhor relacionamento (Fatma e Polícia Ambiental).

No que diz respeito ao relacionamento com o órgão estadual responsável pela formulação da política ambiental estadual (SDS), 40\% dos municípios entrevistados alegaram não ter contato. O mesmo ocorreu com o Ministério do Meio Ambiente, Ibama e ICMBio; ou seja, os órgãos municipais têm pouco contato, como se observa na Tabela 3.

Quando perguntados sobre quem mais contribuiu no processo de criação do órgão municipal, verificou-se que o órgão responsável pela execução da política ambiental no estado (Fatma) foi o mais citado, com $42 \%$. Nesse ponto, embora a maioria dos municípios tenha atribuído à ineficiência do órgão estadual o principal motivo para criar o órgão municipal de meio ambiente, percebe-se que para sua implementação o apoio do órgão estadual foi importante.

Esse dado não chega a ser uma contradição, pois a ineficiência alegada pelos municípios está relacionada principalmente ao tempo demandado para os 




Gráfico 2: Motivo principal para criação do órgão municipal de meio ambiente

Fonte: Dados coletados na pesquisa de campo, 2009.

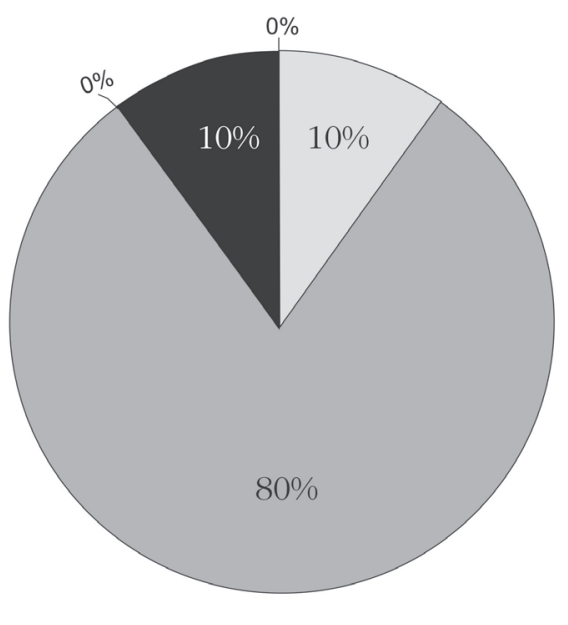

$\square$ Recomendação Gov. Estadual $0 \%$

$\square$ Desconhecimento de outras formas 0\%

$\square$ Exemplo de outros municípios $10 \%$

$\square$ Necessidade de maior autonomia e independência 80\%

Outro $10 \%$

Gráfico 3: Motivo da escolha de Fundação em vez de Secretaria Municipal de Meio Ambiente

Fonte: Dados coletados na pesquisa de campo, 2009. 
Quadro 3: Instrumentos criados conjuntamente com a Fundação

\begin{tabular}{|l|c|c|c|c|c|}
\hline \multicolumn{1}{|c|}{ Município } & \multicolumn{5}{c|}{ Órgão ambiental criado com qual instrumento? } \\
\hline & $\begin{array}{c}\text { Conselho } \\
\text { de MA }\end{array}$ & $\begin{array}{c}\text { Política } \\
\text { Municipal }\end{array}$ & $\begin{array}{c}\text { Fundo } \\
\text { Municipal } \\
\text { de MA }\end{array}$ & $\begin{array}{c}\text { Código } \\
\text { Ambiental } \\
\text { Municipal }\end{array}$ & $\begin{array}{c}\text { Não se } \\
\text { aplica* }\end{array}$ \\
\hline Criciúma & $\mathrm{X}$ & $\mathrm{X}$ & $\mathrm{X}$ & & \\
\hline Cocal do Sul & $\mathrm{X}$ & $\mathrm{X}$ & $\mathrm{X}$ & & \\
\hline Forquilhinha & $\mathrm{X}$ & & $\mathrm{X}$ & & \\
\hline Içara & $\mathrm{X}$ & $\mathrm{X}$ & $\mathrm{X}$ & & \\
\hline Lauro Müller & $\mathrm{X}$ & & & & \\
\hline Morro da Fumaça & $\mathrm{X}$ & $\mathrm{X}$ & $\mathrm{X}$ & & \\
\hline Sangão & & & & & $\mathrm{X}$ \\
\hline Tubarão & & & & & $\mathrm{X}$ \\
\hline Urussanga & & $\mathrm{X}$ & $\mathrm{X}$ & & \\
\hline Itapema & & & & & $\mathrm{X}$ \\
\hline
\end{tabular}

Fonte: Dados coletados na pesquisa de campo, 2009.

*Não se aplica devido ao fato de estarem em processo de criação (Sangão e Tubarão) ou não foi informado no questionário (Itapema).

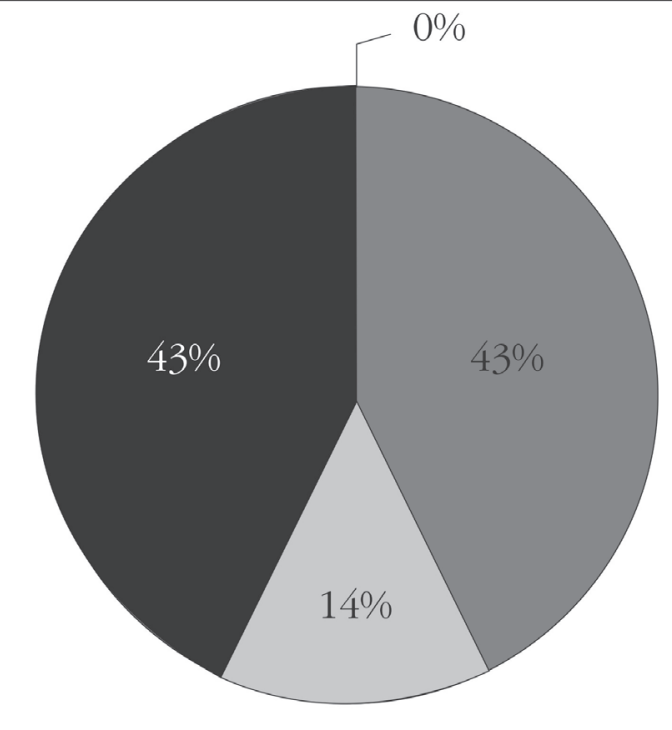

Muito questionamento e debatida amplamente 43\%

Questionamento normal como outros setores 14\%

Foi discutida sem posicionamentos contrários 43\%

Sem discussão - 0\%

\section{Gráfico 4: Processo de discussão junto à Câmara de Vereadores}

Fonte: Dados coletados na pesquisa de campo, 2009. 
Tabela 3: Relacionamento do órgão municipal de meio ambiente com os demais integrantes do Sisnama

\begin{tabular}{|c|c|c|c|c|}
\hline \multirow{2}{*}{$\begin{array}{c}\text { Órgãos componentes } \\
\text { do Sisnama }\end{array}$} & \multicolumn{4}{|c|}{ Relacionamento das prefeituras } \\
\cline { 2 - 5 } & Bom & Razoável & Ruim & Não tem contato \\
\hline MMA & $11 \%$ & $33 \%$ & $10 \%$ & $56 \%$ \\
\hline Ibama & $20 \%$ & $20 \%$ & $0 \%$ & $80 \%$ \\
\hline ICMBio & $20 \%$ & $0 \%$ & $0 \%$ & $40 \%$ \\
\hline SDS & $30 \%$ & $30 \%$ & $10 \%$ & $0 \%$ \\
\hline Fatma & $40 \%$ & $10 \%$ & $10 \%$ & 0 \\
\hline
\end{tabular}

Fonte: Dados coletados na pesquisa de campo 2009 e adaptado de NASCIMENTO, 2010.

processos de licenciamento ambiental e a sobrecarga de trabalho; enquanto que o apoio para os municípios está ligado à assinatura de convênio e outras questões administrativas, e a orientações e consultas sobre como o município deve proceder.

Antes do início da pesquisa, imaginavase que a troca de experiências e informações entre os municípios era um fator importante, mas apenas dois municípios alegaram esse motivo como o que mais contribuiu para a criação do seu órgão municipal de meio ambiente. (Gráfico 5).

Por fim, de forma a compreender melhor as necessidades atuais dos órgãos municipais de meio ambiente estudados, perguntou-se qual era a maior necessidade para que se tivesse melhor funcionamento do órgão. Como resultado, verificou-se que as maiores necessidades estão relacionadas com mais recursos financeiros e recursos operacionais, como carros e equipamentos para o desenvolvimento das atividades. (Gráfico 6)

Nesse ponto, verifica-se que um dos motivos alegados para a criação das fundações públicas, ou seja, ter maior capacidade de captação de recursos, não tem sido confirmado na prática, corroborando com os argumentos de Dallari (1995), ao afirmar que, embora as fundações tenham maior autonomia para captação de recursos, essa vantagem tem sido superestimada no momento de sua criação.

\section{Considerações finais}

Um dos principais obstáculos para a aplicabilidade dos instrumentos de gestão ambiental é a fragilidade do arcabouço institucional. Apesar de já em curso há quase três décadas, o processo de institucionalização das políticas ambientais no Brasil ainda é problemático (BURSZTYN, 2006).

Se, por um lado, a institucionalização da gestão ambiental é importante, também é preciso reconhecer que apenas institucionalizar (criar leis, decretos, regulamentos, organizações) não definirá a qualidade da gestão ambiental local, que depende de outros fatores como transparência, existência de governança local, comportamento cíclico das políticas públicas, clientelismo, corrupção, patrimonialismo, entre outros. 


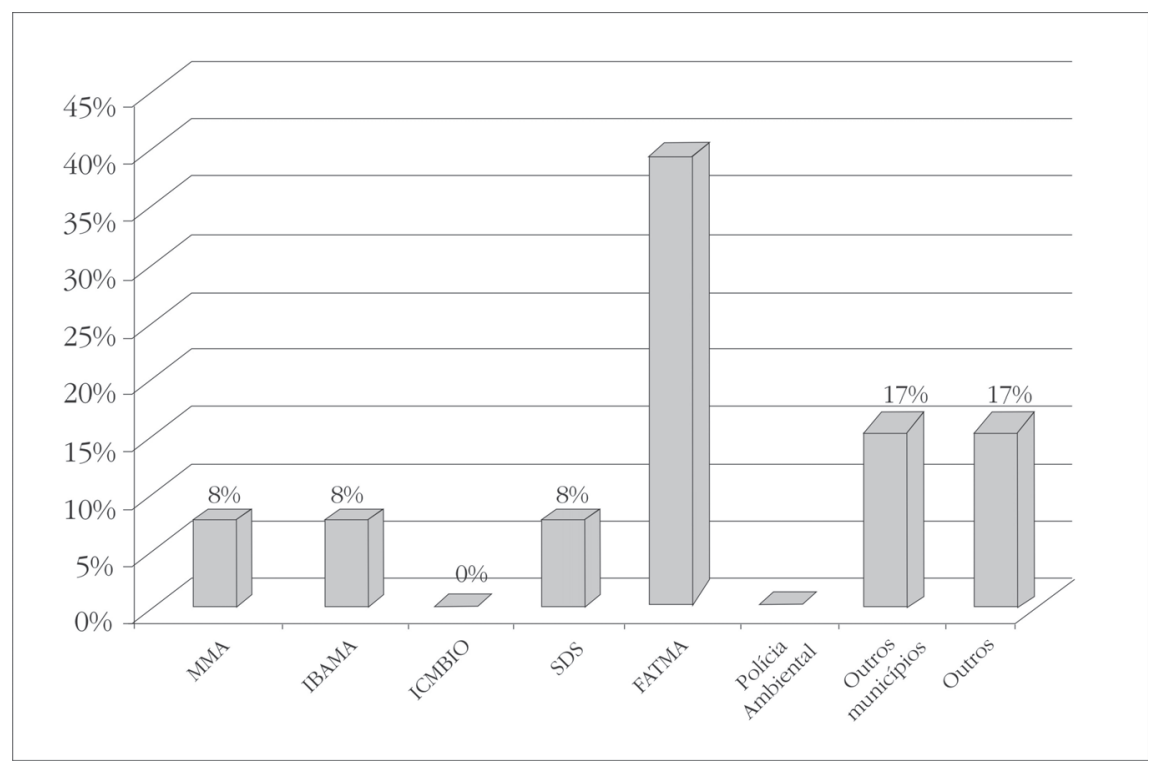

Gráfico 5: Entes que mais contribuíram para a criação do órgão municipal de meio ambiente

Fonte: Dados coletados na pesquisa de campo, 2009.

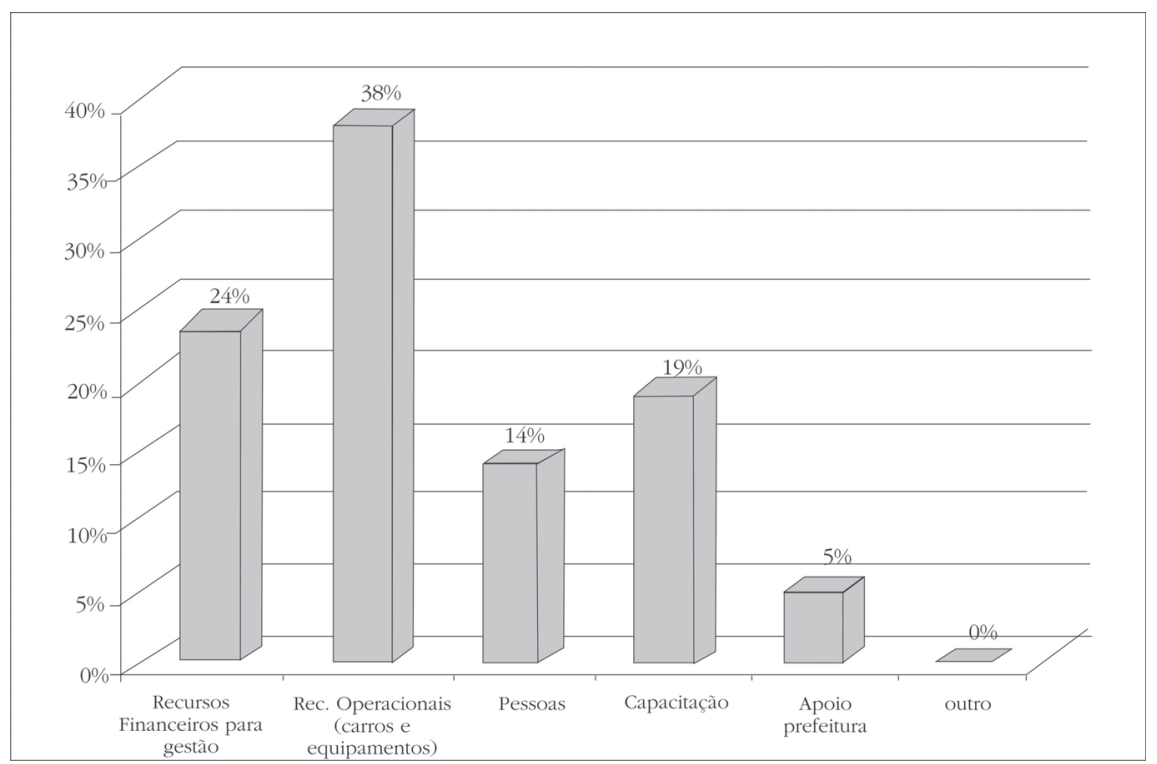

Gráfico 6: Maior necessidade do órgão municipal de meio ambiente

Fonte: Dados coletados na pesquisa de campo, 2009. 
Como apresentado na introdução deste trabalho, foi identificado um processo de crescimento do número de municípios com secretarias de meio ambiente e conselhos municipais nos últimos anos no Brasil. Assim, a fim de verificar alguns dos motivos que têm levado os municípios a institucionalizarem a área ambiental, foi elaborado um estudo sobre a criação das fundações municipais de meio ambiente na região sul de Santa Catarina.

Com esta pesquisa foi possível perceber que a necessidade de maior agilidade nos processos de licenciamento ambiental não é exclusividade de grandes empreendimentos, mais comumente divulgados na mídia, mas também uma necessidade dos empreendedores locais. Foi justamente esse um dos principais fatores que tem contribuído para que o município passe a organizar sua estrutura para a gestão ambiental local e consequentemente para poder proceder ao licenciamento de atividades de impacto local.

Para definir as atividades de impacto local em Santa Catarina, o órgão estadual de meio ambiente, com base no Consema, optou por adotar uma listagem detalhada, levando em consideração o potencial poluidor e de degradação (do solo, água e ar), bem como o porte do empreendimento nas mais variadas atividades.

Também verificou-se nesta pesquisa que a criação do órgão municipal de meio ambiente, na maioria dos municípios estudados, se deu em função da sobrecarga de trabalho e lentidão na emissão de licenças do órgão estadual e da necessidade de agilizar os processos de licenciamento que, de uma certa forma, entravam o estabelecimento de novos empreendimentos nos municípios. Em contraste, é importante notar que apenas um município reconheceu alguma influência do programa estadual de municipalização da gestão ambiental do órgão estadual.

Percebe-se assim que a descentralização da gestão ambiental é um processo complexo e que depende de vários fatores, e não exclusivamente de um programa ou uma política de descentralização. Apesar da importância de programas de descentralização, identificou-se que, ao menos na região estudada, o fator mais decisivo para a criação dos órgãos locais de meio ambiente foi a pressão dos empreendedores locais por processos mais ágeis.

A criação das organizações locais de meio ambiente é importante. Mas ainda existe um desafio que é a estruturação desses entes para poder operar com a agilidade e qualidade esperadas. Como visto no levantamento de dados junto aos municípios estudados, as maiores necessidades das organizações locais recémcriadas têm sido justamente obtenção de recursos operacionais como carros e equipamentos, além de recursos financeiros e capacitação técnica.

Além disso, na habilitação do município para o licenciamento ambiental há a exigência de emprego de alguns instrumentos como conselho de meio ambiente e fundo municipal de meio ambiente. Assim, sabendo que a existência desses instrumentos é um pressuposto fundamental para a governança ambiental, observou-se que essa exigência legal foi fator importante para que as fundações não fossem criadas sem o amparo de instrumentos que fortalecem a institucionalização da gestão ambiental no âmbito local.

Por outro lado, é importante reconhecer que nem sempre a criação formal desses instrumentos (Conselho Municipal de Meio Ambiente e Fundo Municipal de Meio Ambiente, por exemplo) significa 
processo mais transparente e efetivo para a gestão ambiental local, visto que não é raro encontrar conselhos com pouca atividade e fundos desativados, servido apenas como peça figurativa para atender as exigências legais.

Por fim, diante da grandeza e diversidade regional brasileira, é difícil identificar quais são os fatores e forças determinantes para a institucionalização da gestão ambiental no âmbito municipal. Sabe-se que não existe um padrão único. No entanto, a verificação de diversas realidades é um esforço importante para formar uma base de compreensão e, a partir disso, contribuir para a formulação de políticas públicas e tomada de decisão, seja no âmbito federal, estadual ou municipal.

Nesse sentido, este trabalho procurou apresentar a realidade sul catarinense caracterizada pelo surgimento de fundações municipais que funcionam como figuras principais para a área de meio ambiente. Um dos principais motivos para criação de tais entidades se deve à necessidade de processos mais ágeis.

(Artigo recebido em dezembro de 2010. Versão final em setembro de 2011).

\section{Notas}

Foram entrevistadas 15 pessoas de 10 prefeituras e aplicados questionários aos gestores ambientais de cada um dos municípios. Lista de entrevistados: Mirna Murialdo (Consema/SC); Carlos Alberto Cardoso (Cocal do Sul); Sandra Maria de Souza (Cocal do Sul); Adilson Machiavelli (Itapema); Edson Alano (Urussanga); Juliana Turazzi (urussanga); Patricia Mazzon (Urussanga); Ricardo Lino (Içara); Hellen de Souza (Lauro Muller); Julio Cesar Colombo (Criciuma); Joelma Tezza (Criciuma); Paulo Naspolini (Morro da Fumaça); Rui Cesar Rufino (Tubarão); Marco Antônio Remor (Sangão); Edson Tele Campos (Florianópolis).

2 Leis Federais: Art. 23, incisos VI e VII, que trata da competência comum da União, dos estados, do distrito federal e dos municípios para proteger o meio ambiente e combater a poluição em qualquer de suas formas, bem como para preservar as florestas, a fauna e a flora; Art. $225 \mathrm{da}$ Constituição Federal, que enfatiza que todos têm direito ao meio ambiente ecologicamente equilibrado, bem de uso comum do povo e essencial à sadia qualidade de vida, impondo-se ao poder público e à coletividade o dever de defendê-lo e preservá-lo para as presentes e futuras gerações; Artigos $6^{\circ}$ e $9^{\circ}$ da lei federal no 6.938 , de 31/08/81, que tratam da estruturação e órgãos integrantes do Sisnama (Art. $6^{\circ}$ ), bem como dos instrumentos da Política Nacional do Meio Ambiente (Art. $9^{\circ}$ ); Art. 22 da lei federal $n^{\circ} 4.771$, de 15/09/65, onde afirma que a União, diretamente, através do órgão executivo específico ou em convênio com os estados e municípios, fiscalizará a aplicação das normas do Código Florestal; Decreto federal no 750, de 10/02/93, que dispõe sobre o corte, a exploração e a supressão de vegetação primária ou nos estágios avançado e médio de regeneração de Mata Atlântica; Medida provisória n ${ }^{\circ}$ 2.166, de 24/08/2001, que traz alterações no Código Florestal e dispõe sobre o Imposto sobre a Propriedade Territorial Rural (ITR); Resolução Conama no 237/97, que trata sobre o licenciamento ambiental. Leis Estaduais: Artigos 181 e 182 da Constituição Estadual, que reafirma o art. 225 da C. F. e apresenta as atribuições constitucionais do estado na defesa do meio ambiente; Art. $7^{\circ}$ da lei complementar $n^{\circ} 284$ de 28/02/2005, que trata das atribuições dos secretários de Estado; Lei estadual n 5.793 , de 16/10/80, que dispõe sobre a proteção e melhoria da qualidade ambiental e dá outras providências; Art. 120, do decreto estadual nº 14.250 de 05/06/81, que define que a Fatma poderá celebrar convênios com órgãos dos governos federal, estadual e 
municipal com vistas à execução e fiscalização de serviços, na forma da legislação vigente; Decreto estadual n 5.835, de 24/10/2002, que regulamenta o parágrafo único do art. 20 da lei no 10.472; lei $\mathrm{n}^{\circ} 10.720$ de 13 de janeiro de 1998, que dispõe sobre a realização de auditorias ambientais; Protocolo de intenções firmado em 05/06/95, entre o estado, a Fatma, a Polícia Militar do Estado de Santa Catarina e a Federação Catarinense das Associações de Municípios (Fecam); Resolução conjunta 01/95, firmada em 05/04/95, entre o Ibama, o estado de Santa Catarina, através da Secretaria de Desenvolvimento Urbano e Meio Ambiente (SDM), atual SDS, e a Fatma; Portaria Interinstitucional $\mathrm{n}^{\circ}$ 01, de 04/06/96, firmada entre o estado de Santa Catarina através da SDM, o Ibama e a Fatma; Resolução 01/2004 do Consema, que define as atividades potencialmente poluidoras, por meio de listagem, e os critérios para o exercício da competência do licenciamento ambiental municipal; Resolução 02/2006 do Consema, que define as atividades de impacto local para fins do exercício da competência do licenciamento ambiental municipal; Decreto estadual no 3.973 de 4 de fevereiro de 2002, que aprova o Regimento Interno do Conselho Estadual de Meio Ambiente (Consema); Decreto estadual n 620 de 27 de agosto de 2003, que institui o Programa de Descentralização das Ações de Gestão Ambiental no Estado de Santa Catarina, e dá outras providências.

3 Após a realização desta pesquisa, os seguintes municípios criaram suas fundações municipais de meio ambiente: Biguaçu (Famabi), Araranguá (Fama) e Urussanga (Famur).

4 O município de Sangão ainda está em fase de construção tanto da Fundação Municipal de Meio Ambiente, quanto de outros instrumentos e isso já tem gerado muita discussão junto à Câmara de Vereadores.

\section{Referências bibliográficas}

Abreu, R. L. Mapa do Estado de Santa Catarina. Disponível em: http:// pt.wikipedia.org/wiki/Ficheiro:SantaCatarina_MesoMicroMunicip.svg. Acesso em: 07 Jul. 2009.

Azevedo A. A.; Pasquis R.; Bursztyn M. A reforma do estado, a emergência da descentralização e as políticas ambientais. Revista do Serviço Publico (RSP), 58 (1) p. 37-55, 2007. Bursztyn, M. A. Curso de Gestão Ambiental (Programa da disciplina do Curso de Doutorado em Desenvolvimento Sustentável - Universidade de Brasília). Brasília: UNB, 2006. (mimeo)

Dallari, D. D. A. Fundações públicas e suas limitações. Revista Adusp, p. 16-19, 1995.

FGV. Verbetes FGV. FGV, 2008. Disponível em: <http://ead2.fgv.br/ls5/centro_rec/ pag/verbetes/fundacao_publica.htm>. Acesso em: 23 Set. 2009.

Governo do Estado de Santa Catarina. Municípios de SC. 2009. Disponível em: <http://www.sc.gov.br/conteudo/municipios/frametsetmunicipios.htm>. Acesso em: 09 Jun. 2009.

IbGE. Pesquisa de Informações Básicas Municipais (MUNIC). Perfil dos municípios brasileiros: meio ambiente, 2002. Rio de Janeiro: IBGE, 2002.

. Pesquisa de Informações Básicas Municipais (MUNIC). Perfil dos municípios brasileiros - 2008. Rio de Janeiro: IBGE, 2008. 
Instituto Brasileiro de Geografia e Estatística, 2006. Disponivel em: <http://www.ibge.gov.br/home/estatistica/economia/pibmunicipios/2006/ tab01.pdf>. Acesso em: 26 Jun. 2008.

. Produto Interno Bruto dos Municípios 2002-2005. IBGE. 2007. Disponível em: <www.ibge.gov.br>. Acesso em: 12 Out. 2008.

. Mapas interativos do IBGE. IBGE. 2009. Disponível em: <ftp:// geoftp.ibge.gov.br/mapas/tematicos/politico/SC_Politico.pdf>. Acesso em: 23 Jul. 2009a.

. Instituto Brasileiro de Geografia e Estatística, 2008. Disponível em: <http://www.ibge.gov.br/home/estatistica/populacao/estimativa2008/ POP2008_DOU.pdf $>$. Acesso em: 15 Jan. 2009.

. Censo Populacional 2010. Instituto Brasileiro de Geografia e Estatística, 2010.

Marcato, C.; Ribeiro, J.C.J. Manual Gestão Ambiental Municipal em Minas Gerais. 2a ed. FEAM: Belo Horizonte, 2002.

Nascimento, D. T. O papel dos conflitos socioambientais e de eventos climáticos extremos na institucionalização da Gestão Ambiental Municipal. (Tese de Doutorado defendida no Centro de Desenvolvimento Sustentável da Universidade de Brasília). Brasília, 2010.

Novaes, W. A Amazônia, vilã ou vítima? Espaço Aberto. Jornal O Estado de São Paulo, 14 Dez. 2007.

Pnud. Atlas do Desenvolvimento Humano. PNUD, 2000. Disponível em: <www.pnud.org.br>. Acesso em: 12 Out. 2008.

PhiLippi JR, A. Unesp debate com prefeitos gestão ambiental e estatuto da cidade. Informativo Acadêmico. Disponível em < http://www.uniesp.edu.br/informativo 05-2.php?codigo=79> .Acesso em: Dez. 2007.

Purcell, M.; Christopher, J B. Against the local trap: scale and the study of environment and development. Progress in Development Studies v. 5, n. 4, p. 279-297, 2005.

Scardua, F. P. Bursztyn, M. A. A. Descentralização da Política Ambiental no Brasil. Sociedade e Estado (Meio Ambiente, desenvolvimento e sociedade), v. 18, n. 1/2, p.291314, jan./dez. Brasília: UnB, 2003.

Scheibe, L. F. et. al. Projeto Qualidade Ambiental da Região Sul Catarinense. 2006. Disponível em: <http://www.cfh.ufsc.br/ laam/> Acesso em: 17 jun. 2009.

Silva, G.; Silva, D.; Novaes, F. Jusprodivm, 2008. Disponivel em: < http:// www.juspodivm.com.br>. Acesso em: 01 Out. 2009.

SouzA, E. C. B. et all. Desafios da gestão ambiental nos municípios. In: LITTLE, Paul (org). Politicas Ambientais no Brasil. Parte II: Políticas ambientais locais e Participativas. São Paulo, Peirópolis; Brasília, IIEB, 2003.

Teixeira, H. J. Santana, S. M. Remodelando a gestão pública. São Paulo: Ed. Edgard Blücher Ltda: 1995. 


\section{Resumo-Resumen-Abstract}

\section{Descentralização da gestão ambiental: análise do processo de criação de organizações} municipais de meio ambiente no sul catarinense

Daniel Trento do Nascimento e Maria Augusta Almeida Bursatyn

Esta pesquisa está inserida na temática da descentralização da gestão ambiental no Brasil e trata de analisar os principais motivos que têm levado os municípios a institucionalizarem a área ambiental no âmbito local. Para tanto, foram selecionados municípios da região sul catarinense, tendo em vista o processo recente de criação de órgãos locais de gestão ambiental e também a peculiaridade de a grande maioria desses municípios estarem optando pelo estabelecimento de fundações públicas municipais de meio ambiente. Como resultado da investigação, se percebeu que um dos fatores principais para a criação de organizações municipais de gestão ambiental tem sido a necessidade de maior agilidade nos processos de licenciamento ambiental. Em relação à opção pela figura jurídica das fundações, o principal argumento dos municípios tem sido a maior autonomia e independência em relação ao Executivo municipal para a execução de suas ações.

Palavras-chave: descentralização; gestão ambiental municipal; fundações públicas.

\section{Descentralización de la gestión ambiental: análisis del proceso de creación de} organizaciones ambientales municipales en el sur de Santa Catarina

Daniel Trento do Nascimento y Maria Augusta Almeida Bursatyn

Esta investigación científica se inserta en el tema de la descentralización de la gestión ambiental en Brasil y busca analizar las principales razones que han llevado los municipios a la institucionalización del sector de medio ambiente a nivel local. Con tal fin, se seleccionaron las ciudades del sur de Santa Catarina, teniendo en vista el reciente proceso de creación de organizaciones de gestión ambiental local y también por tener la peculiaridad de que la gran mayoría de estos municipios están optando por la creación de fundaciones públicas municipales. Como resultado de la investigación, se dio cuenta de que uno de los factores mas importantes para la creación de organizaciones ambientales municipales ha sido la necesidad de una mayor agilidad en los procesos de licenciamiento ambiental. En relación a la elección de la forma jurídica de fundaciones, el principal argumento de los municipios ha sido la mayor autonomía e independencia del Ejecutivo municipal para llevar a cabo sus acciones.

Palabras clave: descentralización; gestión ambiental municipal; fundaciones públicas.

\section{Environmental management decentralization: analysis of the creation process of municipal environmental organizations in southern Santa Catarina \\ Daniel Trento do Nascimento and Maria Augusta Almeida Bursztyn}

This research is inserted in the subject of environmental management decentralization in Brazil and tries to analyze the main reasons that has led municipalities to institutionalize the environmental sector at local level. Therefore, it was selected municipalities in the South of Santa Catarina based on its recent process of creation of local environmental management organizations and also the peculiarity that the vast majority of the studied municipalities are opting for the establishment of municipal public environmental foundations. As a result of the investigation, it was realized that one of the main factors for the creation of municipal environmental organizations has been the need to speedup the processes of environmental licensing. Regarding the choice public foundations as legal form, the main argument of the municipalities has been the higher autonomy and independence from the municipal executive central power to carry out their actions.

Keywords: decentralization; municipal environmental management; public foundations. 
Daniel Trento do Nascimento

Mestre em Administração pela Universidade Federal de Santa Catarina (UFSC), Especialista em Gestão Local e Serviços Públicos pela Ryukoku University do Japão e Doutor em Desenvolvimento Sustentável pela Universidade de Brasília (UnB). Atualmente é Técnico Especialista do Ministério do Meio Ambiente.

Contato: danieltn@gmail.com

Maria Augusta Almeida Bursztyn

Engenheira Civil pela Universidade de Brasília (UnB), com especialização em Engenharia Sanitária e Ambiental pela École Nationale de la Santé Publique na França; Doutorado em Ciências da Água pela Université de Paris VI e Pós-Doutorado em Avaliação Ambiental na École de Hautes Études en Sciences Sociales da França. Atualmente é professora do Centro de Desenvolvimento Sustentável da Universidade de Brasília (UnB).

Contato: dute.cds@gmail.com 